\title{
Multiobjective Optimization Model for Collaborative En-Route and Slot Allocation
}

\author{
Shangwen Yang $\mathbb{B}$, Jingting Zhang, Ping Chen, and Yongjie Yan \\ State Key Laboratory of Air Traffic Management System and Technology, Nanjing Research Institute of Electronics Engineering, \\ No. 1 Yong Zhi Road, Nanjing 210014, China \\ Correspondence should be addressed to Shangwen Yang; swyang@aliyun.com
}

Received 20 August 2017; Accepted 3 January 2018; Published 31 January 2018

Academic Editor: Thomas Schuster

Copyright (C) 2018 Shangwen Yang et al. This is an open access article distributed under the Creative Commons Attribution License, which permits unrestricted use, distribution, and reproduction in any medium, provided the original work is properly cited.

\begin{abstract}
To allocate the en-routes and slots resource to the flights with collaborative decision-making, a multiobjective 0-1 integer programming model was proposed. According to different demands from air traffic control departments, airlines, and passengers, efficiency, equity, and effectiveness principles of collaborative decision-making were considered. With the aim to minimize the total flight delay costs, the total number of turning points, and average delay time of passengers, the effectiveness constraints were achieved. The algorithm was designed to solve the model on the basis of the objective method, and Lingoll and MatlabR2007b were applied in numerical tests. To test how well the model works in real world, a numerical test was performed based on the simulated data of a civil en-route. Test results show that, compared with the traditional strategy of first come first served, the model gains better effect. The superiority of the model was verified.
\end{abstract}

\section{Introduction}

En-route and slot resource allocation which assigns available en-routes and time slots in coming time period to flights is one of the key technologies of collaborative en-route management. There have been some achievements; typical ones are formulated below. In 2000, Goodhart [1] studied the preferences of airlines during en-route resource allocation when the airspace was confined. In 2005, AFP (Airspace Flow Program) was proposed by FAA (Federal Aviation Administration) [2] and was applied in alleviating air traffic pressure and reducing the influence of adverse weather. In AFP, flights are allowed to flexibly choose suitable en-route. According to real capacity of confined airspace, AFP allocates en-route and slot resource using traditional RBS (Ration-bySchedule) algorithm in accordance with FCFS (first come first served). RBS well embodies the equity of resource allocation. Ball et al. [3] proposed RBD (ration-by-distance) algorithm of which the efficiency was better than RBS and the equity was worse. In 2005, Hoffman et al. [4] proposed an enroute resource allocation method considering airspace users' preferences and air traffic management decisions. In 2009, in the context of AFP, Pourtaklo and Ball [5] proposed an algorithm equitably allocating the en-routes and slots according to flight operators' preferences and their randomicity. Since 2006, AFP has been applied in reducing flight delay and the effect has been verified by practice [6]. However, CTOP (Collaborative Trajectory Options Program) optimally allocating en-route resource with CDM (collaborative decision making) was proposed by FAA and carried out in 2014 [7]. CTOP concentrates on resource attributes of airspace and satisfies flight operators' preferences. In CTOP, different en-routes have different operation costs, and air traffic flow management strategies are introduced in. CTOP uses RBS algorithm and assigns flights holding on the ground or rerouting before entering confined airspace [8]. Market mechanism is also an important way for collaborative en-route and slot allocation. At this time, en-route and slot resource is a type of competitive resource. Market mechanisms such as bid and auction were introduced in en-route, and slot resource allocation was performed according to the need of airlines [9-12]. In 2013, Kim and Hansen [13] proposed 


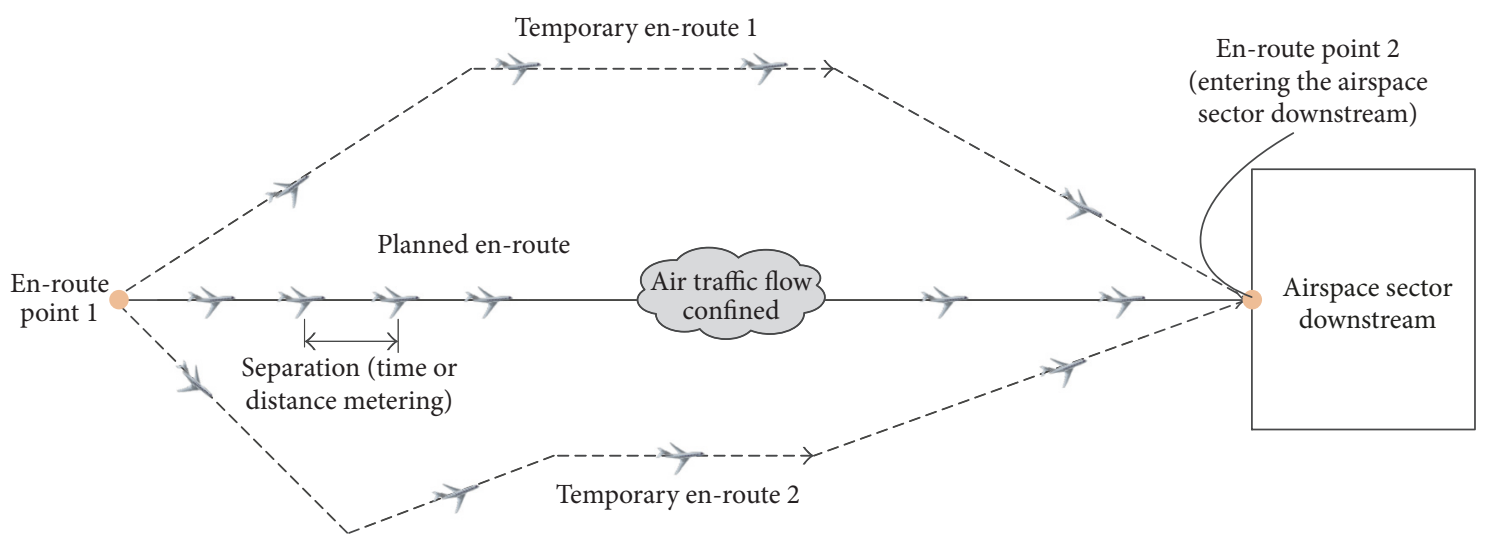

FIGURE 1: The diagram of collaborative en-route operation.

an evaluation model for en-route resource allocation effect. The model holds that there is some uncertainty on operation costs due to flight operators' preferences and analyzes the deviations of delay costs resulting from four typical methods, respectively, that is, FISO (Full Information System-optimal), PASO (Parametric System-optimal), FSFA (First Submitted First Assigned), and RBS. The effect of each method was evaluated in [13]. In 2015, Kim and Hansen [14] proposed an en-route sequential resource allocation model based on game theory. Flight operators could compare the benefits resulting from different time of submitting en-route application, and there was competition about submitting time. It is good for determining the time of submitting en-route application.

In existing achievements, various delay costs are the main index for en-route resource allocation. Although the evaluation ways of delay costs are different, single objective is onesided. The references on multiobjective programming for enroute and slot resource allocation are less seen. Collaborative en-route management refers to the stakeholders such as air traffic control department, airlines, and passengers with the aspects of efficiency, equity, and effectiveness. Delay costs primarily express the efficiency. It is worth establishing multiobjective models expressing the needs of the stakeholders and providing various strategies. In the paper, we proposed a multiobjective 0-1 integer programming model for en-route and slot resource allocation with the aim to minimize the total flight delay costs, the total number of turning points, and average delay time of passengers. The three objectives represent the preferences or interests of these stakeholders. Necessary constraints on en-route capacity, arrival time, and the allocation completeness are also included. To gain noninferior solutions with less complexity, we designed the solving algorithm on the basis of the objective method. The remainder is organized as follows. In Section 2, the operative environment is briefly introduced. In Section 3, the multiobjective model is formulated, and necessary notations are given. In Section 4, the solving algorithm is formulated. In Section 5, a numerical test based on the simulated data of a civil en-route is made to illustrate the efficiency of the model, and necessary analyses are performed. Finally, we conclude in Section 6.

\section{Operative Environment}

As shown in Figure 1, the planned en-route is from en-route point 1 to en-route point 2 . The en-route point 1 is the entry, and the en-route point 2 is the exit as well as the entry to the airspace sector downstream (en-route or controlled sector). When the capacity of the planned en-route decreases due to adverse weather, air traffic flow would be confined. Flight delay would occur. It is a better way to open several temporary en-routes near the planned en-route and divert some flights to temporary en-routes. Then, the flights from the planned en-route and the temporary en-routes would enter the airspace sector downstream at en-route point 2 . When a temporary en-route is established, the features such as cost and range are known. Generally speaking, each en-route is featured by its capacity, delay cost, flight time, and the number of turning points. It is necessary to determine the en-route and the time entering the airspace sector downstream for each flight. Due to the relationship between planned en-route and airspace sector downstream, collaborative en-route and slot allocation model should assign the en-route and slot to a flight efficiently, equitably, and effectively according to the slots of airspace sector downstream and the capacities of the en-routes. The preferences or interests of these stakeholders should be combined, and multiple objectives should be achieved. It aims to alleviate airspace congestion and ensure the clearance of air traffic.

\section{Mathematical Model}

Delay cost is the essential characteristic of the allocation efficiency and is related to the benefits of the airlines. Furthermore, delay costs in the en-routes are different with each other. Generally speaking, delay costs in temporary enroute are more than planned en-route, and the flights with different aircraft types have different delay costs. Then, the objective on allocation efficiency aiming to minimize total delay costs can be formulated as follows.

$$
\min \sum_{i=1}^{I} \sum_{j=1}^{J}\left(c_{s} x_{i j}+\sum_{k=1}^{K} c_{t}^{k} y_{i j}^{k}\right)\left(t_{j}-\mathrm{eta}_{i}\right) \text {. }
$$


In formulation (1), $c_{s}$ represents the delay costs per unit time in planned en-route, and $c_{t}^{k}$ represents the delay costs per unit time in temporary en-route $k(1 \leq k \leq K$, where $K$ is the number of temporary en-routes). $t_{j}(1 \leq j \leq J$, where $J$ is the number of the slots) is the initial time of a slot and represents the slot. eta ${ }_{i}$ represents the estimated time of arrival (ETA) at airspace sector downstream for flight $i(1 \leq i \leq I$, where $I$ is the number of the flights). $x_{i j}$ and $y_{i j}^{k}$ are decision variables, which can be formulated as follows.

$$
\begin{aligned}
& x_{i j}= \begin{cases}1, & \text { slot } j \text { and planned en-route for flight } i, \\
0, & \text { otherwise, }\end{cases} \\
& y_{i j}^{k}
\end{aligned}
$$$$
= \begin{cases}1, & \text { slot } j \text { and temporary en-route } k \text { for flight } i, \\ 0, & \text { otherwise. }\end{cases}
$$

Turning points directly express the complexity of enroutes and the workload of air traffic control. Then, the objective on air traffic control efficiency aiming to minimize the total number of turning points can be formulated as follows.

$$
\min \sum_{i=1}^{I} \sum_{j=1}^{J}\left(r_{s} x_{i j}+\sum_{k=1}^{K} r_{t}^{k} y_{i j}^{k}\right)
$$

In formulation (3), $r_{s}$ represents the number of turning points in planned en-route, and $r_{t}^{k}$ represents the number of turning points in temporary en-route $k$.

Delay time is most concerned by passengers and expresses the quality of airlines service. When flight delay occurs, delay time should be balanced to avoid large delay for part of passengers. Then, the objective on allocation equity aiming to minimize average delay time of passengers can be formulated as follows.

$$
\min \frac{\sum_{i=1}^{I} \sum_{j=1}^{J} n_{i}\left(t_{j}-\text { eta }_{i}\right)\left(x_{i j}+\sum_{k=1}^{K} y_{i j}^{k}\right)}{\sum_{i=1}^{I} n_{i}} .
$$

In formulation (4), $n_{i}$ represents the number of passengers in flight $i$.

Then, the constraints meeting allocation effectiveness can be formulated as follows.

$$
\begin{aligned}
& \sum_{j=1}^{J}\left(x_{i j}+\sum_{k=1}^{K} y_{i j}^{k}\right)=1, \quad 1 \leq i \leq I, \\
& \sum_{i=1}^{I}\left(x_{i j}+\sum_{k=1}^{K} y_{i j}^{k}\right) \leq 1, \quad 1 \leq j \leq J, \\
& t_{j} \geq \text { eta }_{i}, \quad 1 \leq i \leq I, \quad 1 \leq j \leq J, \\
& t_{j} \geq \operatorname{eta}_{i}+\Delta_{k} y_{i j}^{k}, \\
& 1 \leq i \leq I, \quad 1 \leq j \leq J, \quad 1 \leq k \leq K,
\end{aligned}
$$

$$
\begin{aligned}
& \sum_{i=1}^{I} \sum_{j=1}^{J} x_{i j} \leq \mathrm{Ca}_{s}, \\
& \sum_{i=1}^{I} \sum_{j=1}^{J} y_{i j}^{k} \leq \mathrm{Ca}_{t}^{k}, \quad 1 \leq k \leq K .
\end{aligned}
$$

Constraint (5) ensures that there would be only an enroute and a slot for a flight. Constraint (6) ensures that a slot could be assigned to no more than one flight. Constraint (7) ensures that real time of arrival (RTA) at airspace sector downstream would not be earlier than ETA. Constraint (8) ensures that RTA would not be earlier than ETA with the addition of flight time resulting from temporary en-routes, where $\Delta_{k}$ is the additional flight time resulting from temporary en-route $k$. Constraint (9) ensures that air traffic flow would not exceed the capacity of planned en-route, where $\mathrm{Ca}_{s}$ represents the capacity of planned en-route. Constraint (10) ensures that air traffic flow would not exceed the capacity of temporary en-routes, where $\mathrm{Ca}_{t}^{k}$ represents the capacity of temporary en-route $k$.

\section{Algorithm Designing}

Generally speaking, the methods for solving multiobjective optimization include weighted sum method and noninferior method (Pareto-optimal method). The weighted sum method combines all the multiobjective functions into single composite objective function using the weighted sum, and the solutions are affected by the weights. Noninferior method has been widely used. Based on the objective method [15], we successively retained one of the objectives and translated other objectives into the constraints. Then, the multiobjective programming model could be formulated as a single-objective programming model. Mathematical software Lingoll was applied in solving a group of single-objective models. The detailed process of the algorithm is shown in Figure 2.

In the algorithm, larger $\varepsilon$ may result in omitting noninferior solutions, while less $\varepsilon$ may result in the decrease of the algorithm efficiency. It is not clear how to exactly determine the value of $\varepsilon$. Generally speaking, the initial value of $\varepsilon$ is less. Then, the initial value of $\varepsilon$ should be gradually increased to gain all of noninferior solutions according to the need of real simulation.

\section{Numerical Test}

Set the simulated data of a civil en-route as an example. The capacity of the en-route decreased due to adverse weather, and flight delay would be caused. According to available airspace and air traffic control experiences, two temporary en-routes were set. The information of the three en-routes is shown in Table 1 where delay costs per hour are for light (L) flights in each en-route. Medium (M) and heavy (H) flights are, respectively, two times and four times the values of light flights according to experiences. Generally speaking, flight time and delay costs in temporary en-routes are larger than those in planned en-route. In the test, flight time in planned 


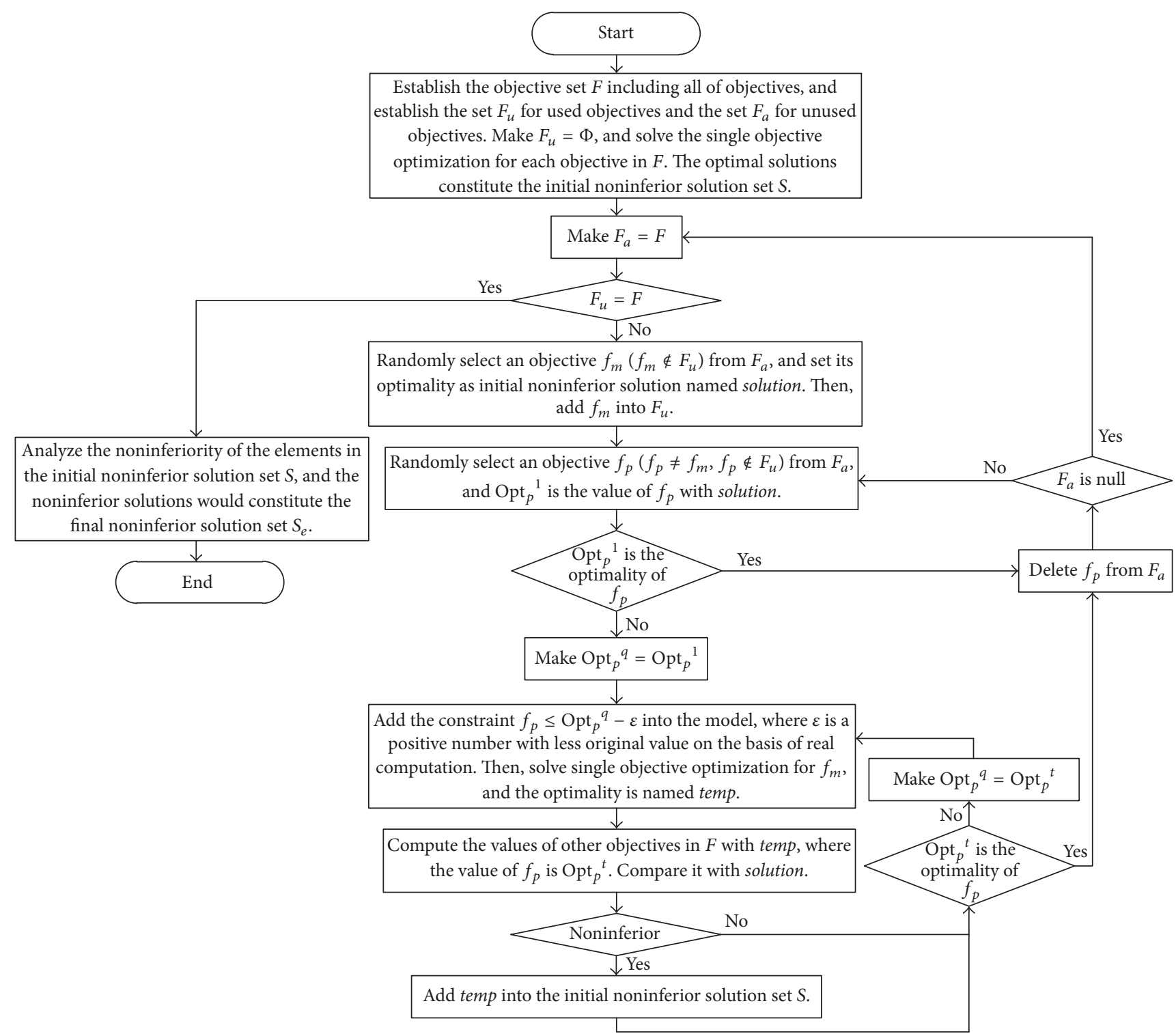

FIgURE 2: The process of the algorithm.

TABLE 1: The information of the en-routes.

\begin{tabular}{lcccc}
\hline Number & En-route & Capacity (flights/hour) & Flight delay costs (yuan/hour) & The number of turning points \\
\hline$(1)$ & Planned en-route & 4 & 2400 & 1 \\
$(2)$ & Temporary en-route 1 & 9 & 3300 & 2 \\
$(3)$ & Temporary en-route 2 & 5 & 2900 & 3 \\
\hline
\end{tabular}

en-route is twenty minutes, and the flight time in temporary en-route 1 and temporary en-route 2 is, respectively, $5 \%$ and $15 \%$ larger than that in planned en-route. The information of the flights is shown in Table 2. The capacity of airspace sector downstream is ten flights per hour, and the length of a slot is six minutes.

Mathematical software Lingoll and MatlabR2007b were applied in solving the model, where MatlabR2007b was used for processing data and creating decision matrices. Noninferior solutions are shown in Figure 3.

FCFS is the typical method for en-route and slot resource allocation and well represents the equity. We perform FCFS using MatlabR2007b, and the allocation strategy is shown in Table 3. The total delay costs, average delay time of passengers, and the total number of turning points are 249840 yuan, 59.61 minutes, and 60, respectively. 


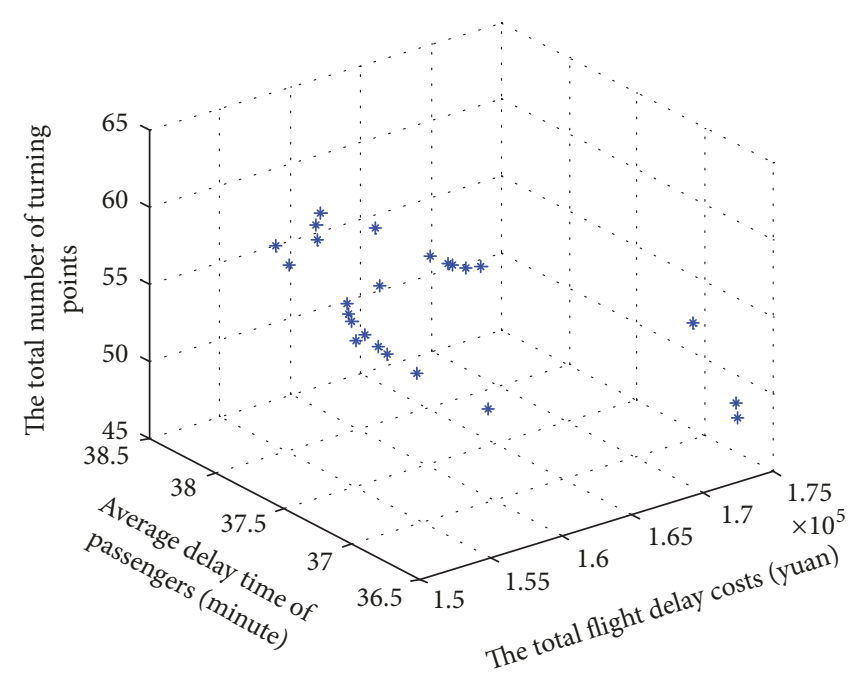

* Pareto-optimal solutions

Figure 3: Test results.

TABLE 2: The information of the flights.

\begin{tabular}{|c|c|c|c|}
\hline Number & Aircraft type & ETA & The number of the passengers \\
\hline (1) & $\mathrm{H}$ & $10: 00$ & 260 \\
\hline (2) & $\mathrm{H}$ & $10: 02$ & 280 \\
\hline (3) & M & 10:04 & 120 \\
\hline (4) & $\mathrm{H}$ & $10: 06$ & 300 \\
\hline (5) & M & $10: 08$ & 110 \\
\hline (6) & M & $10: 10$ & 100 \\
\hline (7) & $\mathrm{H}$ & $10: 12$ & 280 \\
\hline (8) & M & $10: 14$ & 120 \\
\hline (9) & $\mathrm{L}$ & $10: 16$ & 70 \\
\hline$(10)$ & M & $10: 18$ & 140 \\
\hline$(11)$ & $\mathrm{H}$ & $10: 20$ & 300 \\
\hline (12) & M & $10: 22$ & 100 \\
\hline (13) & $\mathrm{H}$ & $10: 24$ & 270 \\
\hline (14) & M & $10: 26$ & 130 \\
\hline$(15)$ & M & $10: 28$ & 140 \\
\hline (16) & $\mathrm{H}$ & $10: 30$ & 290 \\
\hline$(17)$ & $\mathrm{H}$ & $10: 32$ & 250 \\
\hline (18) & $\mathrm{L}$ & $10: 34$ & 70 \\
\hline (19) & $\mathrm{H}$ & $10: 36$ & 300 \\
\hline (20) & $\mathrm{H}$ & $10: 38$ & 260 \\
\hline (21) & $\mathrm{H}$ & $10: 40$ & 280 \\
\hline (22) & $\mathrm{H}$ & $10: 42$ & 240 \\
\hline (23) & $\mathrm{M}$ & $10: 44$ & 130 \\
\hline (24) & M & $10: 46$ & 150 \\
\hline (25) & $\mathrm{H}$ & $10: 48$ & 280 \\
\hline (26) & $\mathrm{L}$ & $10: 50$ & 70 \\
\hline (27) & $\mathrm{H}$ & $10: 52$ & 250 \\
\hline (28) & M & $10: 54$ & 130 \\
\hline (29) & $\mathrm{H}$ & $10: 56$ & 270 \\
\hline (30) & $\mathrm{H}$ & $10: 58$ & 300 \\
\hline
\end{tabular}

For the noninferior solutions in Figure 3, the average values of the total delay costs, average delay time of passengers, and the total number of turning points are 158748.75 yuan, 37.39 minutes, and 56.46 , respectively.

It can be seen from test results that the model proposed is remarkably better than FCFS and takes account of the efficiency and equity. The model formulates the objectives representing the interests of the stakeholders such as air traffic control department, airlines, and passengers and provides various strategies. The algorithm is easy to perform. In the numerical test, Lingoll completely solved each singleobjective programming using branch and bound.

\section{Conclusion}

According to the efficiency, equity, and effectiveness principles of collaborative decision-making as well as the stakeholders such as air traffic control departments, airlines, and passengers, we proposed a multiobjective $0-1$ integer programming model for en-route and slot resource allocation with the aim to minimize the total flight delay costs, the total number of turning points, and average delay time of passengers. We performed the numerical test based on the simulated data of a civil en-route with Lingoll and MatlabR2007b. Test results show superiority of the model. Collaborative en-route management refers to various stakeholders, decision-making demands, and airspace environment. Next research would consider more decision objectives and propose mathematical models or algorithms being fit for different en-route operation conditions.

\section{Conflicts of Interest}

The authors declare that there are no conflicts of interest regarding the publication of this paper. 


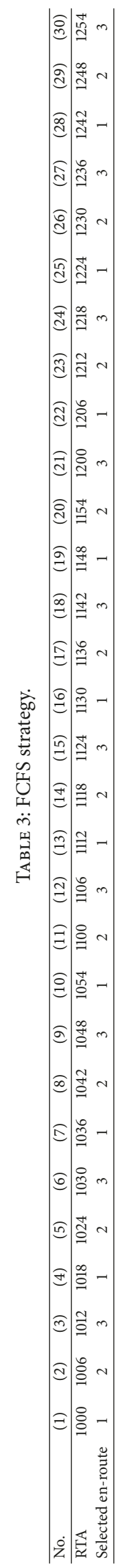




\section{References}

[1] J. Goodhart, Increasing Airline Operational Control in a Constrained Air Traffic System, University of California, Berkeley, Calif, USA, 2000.

[2] M. Libby, J. Buckner, and M. Brennan, Operational Concept for Airspace Flow Programs (AFP), FAA Air Traffic Organization, Washington, DC, USA, 2005.

[3] M. O. Ball, R. Hoffman, and A. Mukherjee, "Ground delay program planning under uncertainty based on the ration-bydistance principle," Transportation Science, vol. 44, no. 1, pp. 1$14,2010$.

[4] R. Hoffman, J. Burke, T. Lewis, A. Futer, and M. Ball, "Resource allocation principles for airspace flow control," in AIAA Guidance, Navigation and Control Conference and Exhibit, San Francisco, Calif, USA, 2005.

[5] N. V. Pourtaklo and M. Ball, "Equitable allocation of enroute airspace resources," in Eighth USA/Europe Air Traffic Management Research and Development Seminar (ATM2009), Napa, Calif, USA, 2009.

[6] FAA, FAA Greatly Expands Air Traffic Program to Minimize Summer Delays[R], 2007, http://www.faa.gov/news/press_ releases/news_story.cfm?newsID $=8889$.

[7] FAA, AC 90-115 - Collaborative Trajectory Options Program (CTOP): Document Information[R]. Federal Aviation Administration. June 24, 2014, http://www.faa.gov/documentLibrary/media/Advisory_Circular/AC-90-115.pdf".

[8] FAA, FAA Industry Forum 2012 Post Event Website. FAA CTOP Presentation for Aviation Forum 2012 - Final.pdf [R]. "http://faaindustryforum.org/4" (accessed 01.09.13).

[9] S. L. Waslander, R. L. Raffard, and C. J. Tomlin, "Marketbased air traffic flow control with competing airlines," Journal of Guidance, Control, and Dynamics, vol. 31, no. 1, pp. 148-161, 2008.

[10] S. L. Waslander, K. Roy, R. Johari, and C. J. Tomlin, "LumpSum Markets for Air Traffic Flow Control With Competitive Airlines," Proceedings of the IEEE, vol. 96, no. 12, pp. 2113-2130, 2008.

[11] L. Castelli, R. Pesenti, and A. Ranieri, "The design of a market mechanism to allocate Air Traffic Flow Management slots," Transportation Research Part C: Emerging Technologies, vol. 19, no. 5, pp. 931-943, 2011.

[12] A. Kim, Collaborative Resource Allocation Strategies for Air Traffic Flow Management, Civil and Environmental Engineering, University of California, Berkeley, Calif, USA, 2011.

[13] A. Kim and M. Hansen, "A framework for the assessment of collaborative en route resource allocation strategies," Transportation Research Part C: Emerging Technologies, vol. 33, pp. 324-339, 2013.

[14] A. Kim and M. Hansen, "Some insights into a sequential resource allocation mechanism for en route air traffic management," Transportation Research Part B: Methodological, vol. 79, pp. 1-15, 2015.

[15] X. S. Yuan, D. H. Shao, and S. L. Yu, Application of LINGO and Excel in Mathematical Modeling, Science Press, Beijing, China, 2007. 


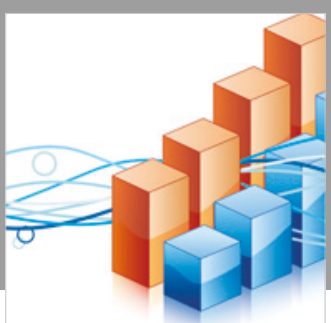

Advances in

Operations Research

\section{-n-m}
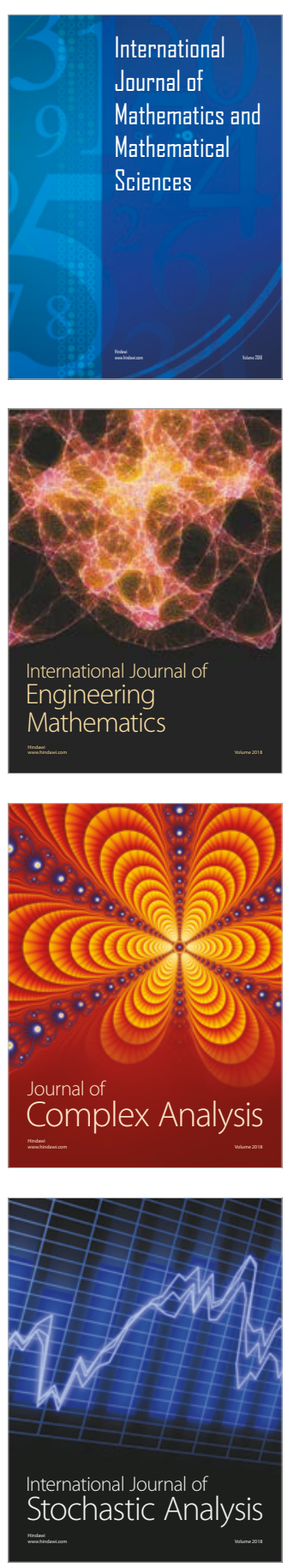
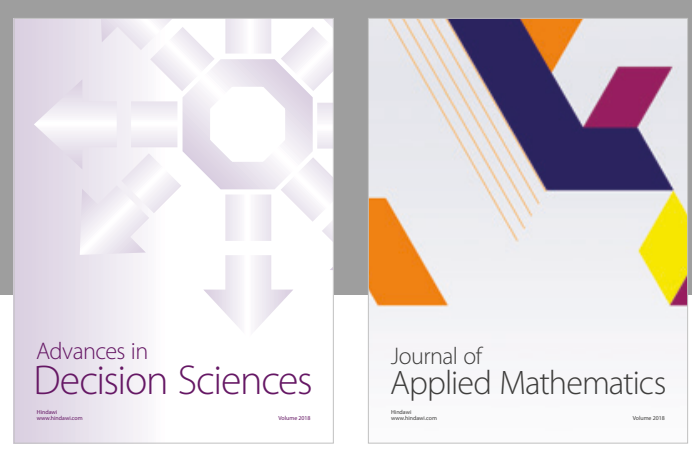

Journal of

Applied Mathematics
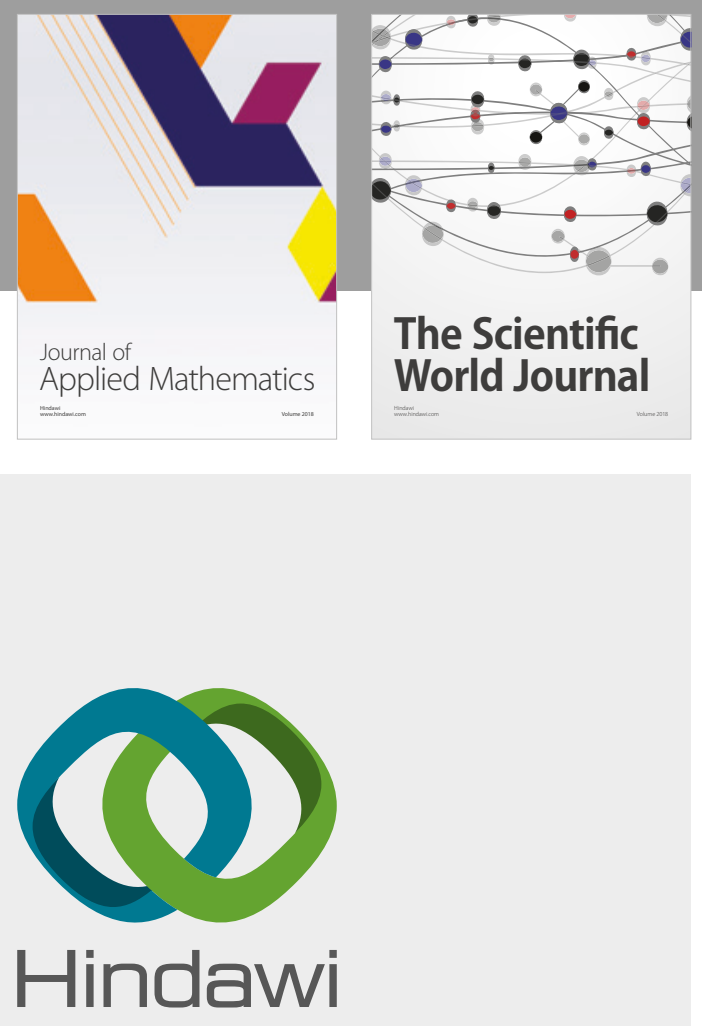

Submit your manuscripts at

www.hindawi.com

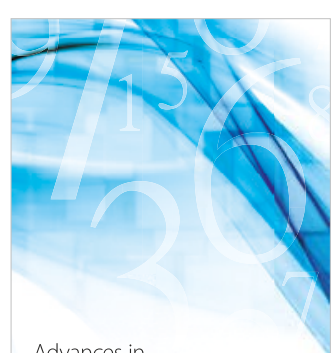

Advances in
Numerical Analysis
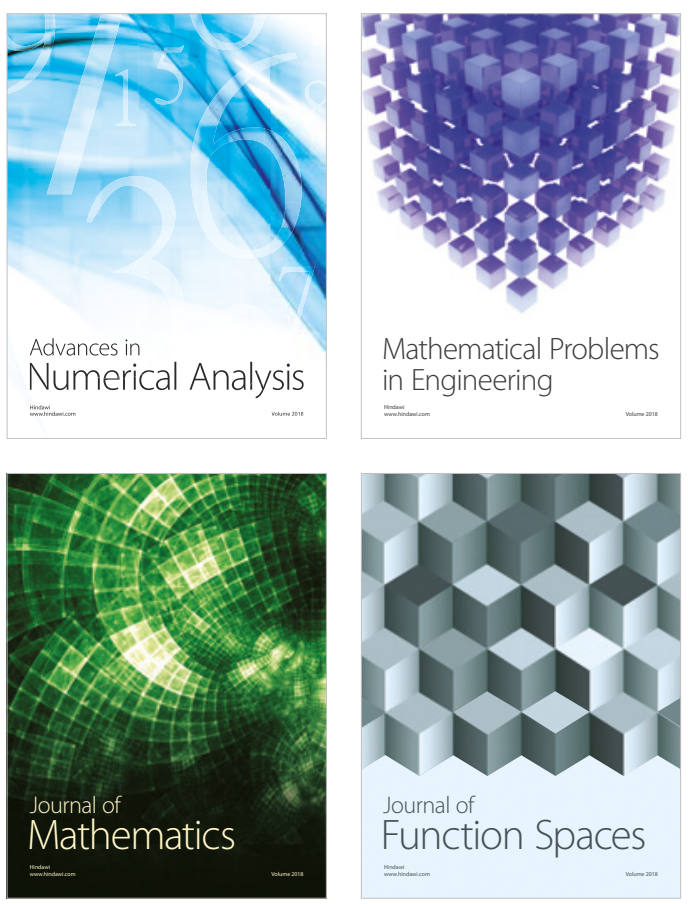

Mathematical Problems in Engineering

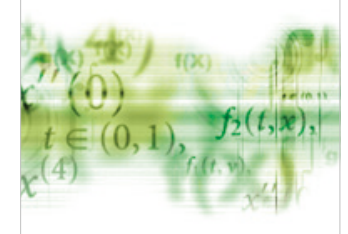

International Journal of

Differential Equations

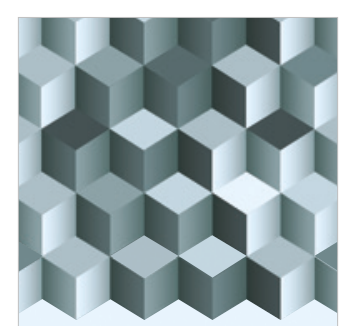

Journal of

Function Spaces

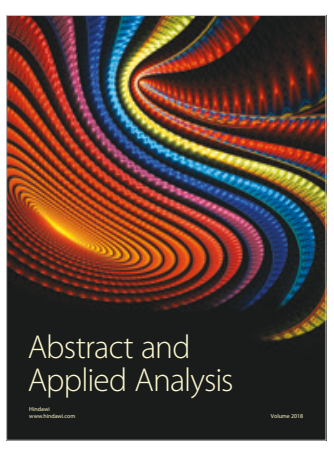

The Scientific

World Journal

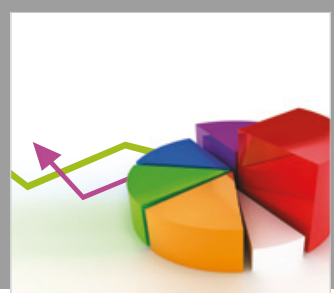

Journal of

Probability and Statistics
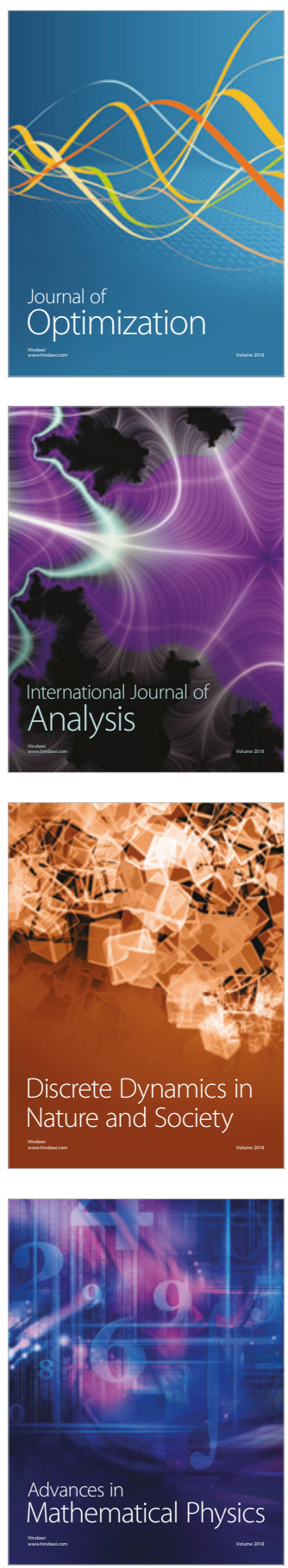